\title{
Decommissioning Plans for Fixed Offshore Platforms: A Brief Revision
}

\author{
Marcio Soares Pinheiro ${ }^{1}$ and Paulo Roberto Duailibe Monteiro ${ }^{2}$ \\ ${ }^{1}$ Faculty of Engineering, Fluminense Federal University \\ Niteroi, Brazil \\ Email: mspinheiro [AT] id.uff.br \\ ${ }^{2}$ Faculty of Engineering, Fluminense Federal University \\ Niteroi, Brazil \\ Email: pauloduailibe [AT] id.uff.br
}

\begin{abstract}
Brazil began to explore its seas in the 60's of the XX Century looking for petroleum. This journey began in the Northeast and the first oil field produced offshore was the Guaricema Field, in the State of Sergipe. During the 70's, Petrobrás found oil in the Campos Basin, between the States of Espírito Santo and Rio de Janeiro, that became the most important oil province in Brazil until the discovery of the Pre-Salt province, in the Santos Basin. As these fields are producing for a long time, many of them are already completely depleted or their production is in way of to be not commercial anymore, and their facilities need to be decommissioned. This review of decommissioning practices of fixed offshore platforms carried out worldwide has focus on the removal of topside with special vessels designed for this purpose or with conventional methods (crane vessels + barge). It will show the benefits of using specialised heavy lift vessels to remove the topsides and move it to shore for dismantling / recycling / reuse / disposal. The cases for study were the successful decommissioning projects in the North Sea: Brent B/D, Valhall QP, Viking, Curlew, Eider A, Golden Eye and Leman, Iwaki-Oki, Halfweg Q1, Yme and Ninian North.
\end{abstract}

Keywords-Offshore, Decommissioning, Oilfield, Dismantling

\section{INTRODUCTION}

Decommissioning is the process by which an industrial installation is deactivated and dismantled, with the objective of returning to the condition closest to the original, covering in an integrated legal, environmental and safety requirements through engineering procedures (definition by the author).

Normally carried out at the end of the installation's useful life, decommissioning represents the last milestone of an offshore oilfield production project, where there is a more significant cost that must be considered in the economic assessment in the implementation phase, once that occurs after the project's revenue generation ceases.

In Brazil, a series of oil fields are exhausted or at the end of their commercial viability, especially on the Northeast coast and in the Campos Basin and their systems and subsystems are already being prepared to be decommissioned. Of the more than 160 offshore units, 67 of them have been in operation for more than 25 years and another 24 have been in operation for 15 to 25 years, which reveals an expected horizon for decommissioning offshore platforms lasting decades.

There are several options for the destination of the platforms when planning their decommissioning, as indicated in the Fig. 1, and the strategy to accomplish this task depends a lot on the reuse opportunities. 

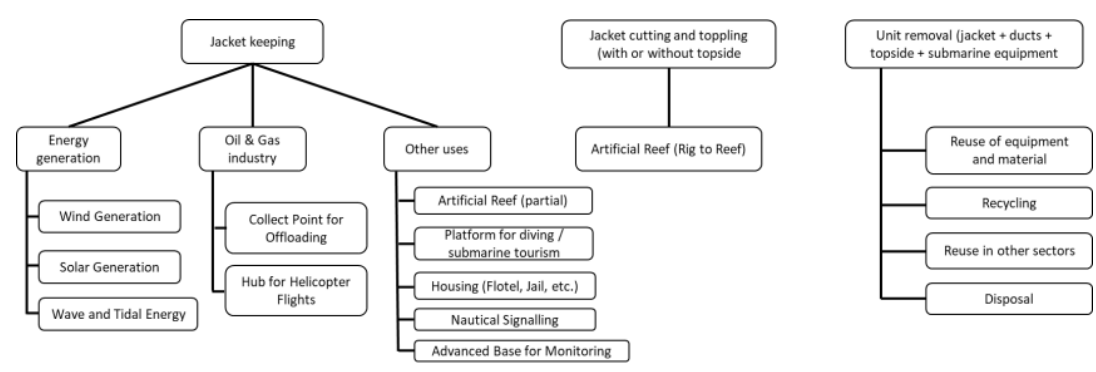

Figure 1 Reuse guides the decommissioning strategies

In this work, a review of the related literature available is made to evaluate the options for removing the topside from fixed units, using vessels specialized in this type of activity or with conventional methods of removing these structures.

\section{PREPARATION FOR DECOMMISSIONING}

An offshore fixed platform decommissioning project covers the following phases:

- Declaration of Cessation of Production (CoP);

- Issue of the decommissioning plan to the competent authority;

- Well plugging and abandonment (P\&A);

- Duct cleaning (flushing and pigging);

- Disconnection and removal of structures;

- Removal of subsea systems;

- Dismantling / reusing of removed structures;

- Monitoring of plugged wells and disposals.

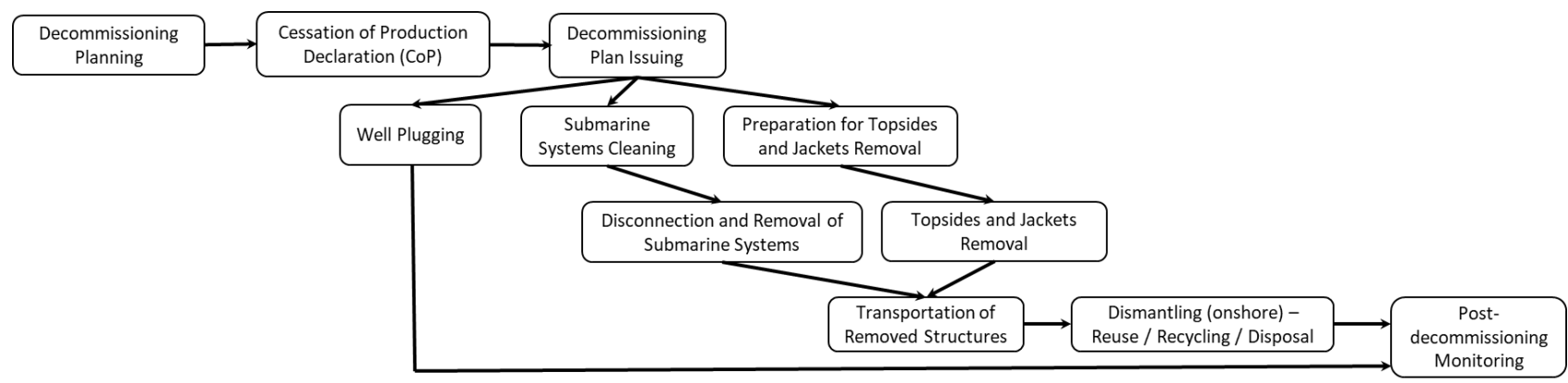

Figure 2 Simplified decommissioning project for a fixed platform

The Cessation of Production declaration $(\mathrm{CoP})$ is a notice sent to the national authority responsible for the inspection of hydrocarbon mining activities, where the platform operator informs about the interruption of production at that unit. In Brazil, for example, it would be the National Petroleum Agency (ANP).

ANP (in other countries, the respective national authority) is responsible to approve the decommissioning plan, which must cover all phases until the return of the granted area with the environmental recovery and the final destination of the platform and the entire associated system.

Well plugging and abandonment (P\&A) is the next step, to allow the disconnection of production and injection lines and removal of subsea systems, such as wellheads, Blowout Preventers (BOP), wet Christmas trees, Pipeline End Manifolds (PLEM), Pipeline End Terminals (PLET), pipelines, among others. For this, a special grout is inserted in the wells, which after drying, shall be monitored to ensure that there is no hydrocarbon leakage.

Afterwards, still taking advantage of the platform's facilities, duct cleaning is carried out by pig running and / or flushing. As the risk of contamination by oil was mitigated in the previous phases, it is possible to start the disconnection of subsurface systems, ducts, umbilical and platform equipment (in the case of a strategy of reverse or hybrid disassembly, sometimes called Heavy Lift method).

For the topside removal strategy, either by single lift removal or reverse disassembly, it is necessary to make sure that no loose or moving parts will come loose during movement. By this way, there is an earlier phase of preparation for the lifting / jacking of the topside, which includes locking or removal of moving and loose parts, draining of liquids internal to pipes, vessels and other equipment, flushing of pipes and ventilation tanks and other confined spaces. 


\section{STUDIED CASES}

The studied topsides decommissioning projects can be divided into two groups: Removal in parts or removal by single lift. The removal in parts can be subdivided into: Disassembly into small pieces or reverse disassembly with heavy lift, which differ by the capacity of the vessels involved, such as the Eider Alpha, Iwaki-Oki and Leman BH projects. Removal by single lift, which normally needs a specialized vessel, as done for the Brent Bravo / Delta [6] and Valhall QP $[10,11]$ projects, can be carried out by lifting or pushing up.

In any of the used methods, a division of the main parts is done, with a cut being made at the top of the jacket, above the waterline.

\subsection{Group I - Removal in parts:}

\subsubsection{Eider Alpha: Using crane barges and deck barges (planned)}

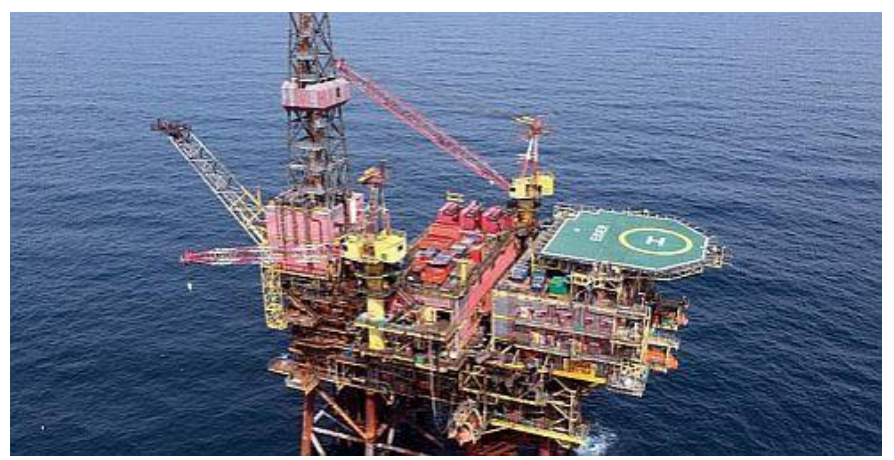

Figure 3 Platform Eider Alpha [8]

Eider Alpha is an example of jacket structure reusing for another activity linked to offshore activities. As this platform was no longer economically viable as an oil production unit, the strategy adopted was to convert it into a utility unit to support adjacent facilities, since the company that owns this unit has a lifespan extension program for the fields it operates in the surroundings, using new Enhanced Oil Recovery (EOR) techniques. Thus, there was a postponement of the decommissioning activities for the entire unit, including its jacket, piping and subsurface equipment, scheduled now for 2026. [19]

The decommissioning process of this unit has already started with the completion of Engineering studies, the interruption of production, CoP issuing, wells plugging and underwater lines cleaning (flushing), as legal requirements of the British environmental agency policy, since this unit is no longer an oil and gas production purposes.

The topside to be removed from the Eider Alpha weighs 11,606 t, of which about $731 \mathrm{t}$ is hazardous waste, such as asbestos, heavy metals, radioactive material, among others, and consists of five modules. Three topside disassembly strategies are being analysed: single removal, reverse disassembly and a hybrid model using both previous processes (also known as Heavy Lift method). The focus for the decommissioning residues was to reuse equipment whenever possible and recycle the rest.

\subsubsection{Iwaki-Oki: Using heavy lift vessel and deck barges}

The Iwaki-Oki platform, in Japan, used the reverse disassembly process, with the Sapura 3000 heavy lift vessel, whose lifting capacity is up to 3,000 t [5]. The topside was removed in nine modules between 300 and $600 \mathrm{t}$, some smaller pieces and a heavier support module, of 1,076 t (Fig. 5B). [2]

This is a slower process and requires more support barges. In the specific case, there were four barges to take off the entire topside. 


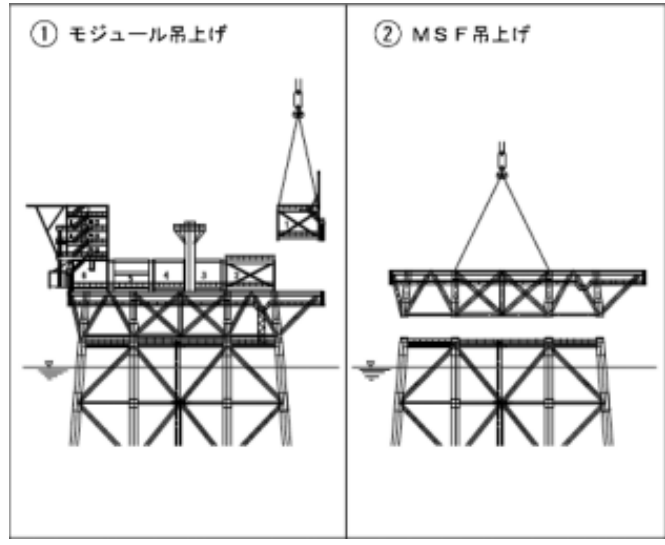

Figures 4 and 5 Iwaki-Oki platform topside removal process [3]

For the final destination of the Iwaki-Oki jacket, the Rig-to-Reef solution was used, where the jacket was cut at a height of $92.5 \mathrm{~m}$ above the seabed with the support of an ROV, the upper part of the jacket was moved to the side and toppled.

\subsubsection{Miller and North West Hutton: Using heavy lift vessel and deck barges}

The North West Hutton platform in the North Sea used a reverse disassembly process, similar to Iwaki-Oki, but with heavier modules. This disassembly required 22 lifts, which took 90 days to remove the 28,000 t topside. The vessel used was Hermod semi-submersible Heavy Lift, with a lifting capacity up to 9,000 t, which transferred the modules to deck barges for later transfer to land. [12]

The jacket was cut into 58 parts, using the techniques of hydraulic scissors, diamond wire and abrasive water jets, totalling 9,200 t of steel removed for the barges and sent for dismantling on land, leaving only the platform bases on the seabed;

Miller's platform had a process similar to North West Hutton, but divided into just 12 modules, totalling 28,700 t. Saipem 7000 semi-submersible Heavy Lift was used, with a lifting capacity of up to 7,000 t $(14,000 \mathrm{t}$ in tandem), consuming only about 30 days. For the jacket, the strategy was the same as done for North West Hutton, with only footings remaining on the seabed.

Small pieces method does not require special vessels, which have more limited availability windows and generally have more expensive freight. However, it has some disadvantages, such as the longer duration of the operation and the consequent needs for a larger workforce, for accommodation, greater susceptibility to weather and sea conditions, more complicated logistics, increased need for harbour services, etc.

\subsection{Group II - Single Lift Removal}

The methods of single lift removal, either topside or jacket, require special equipment for their execution, but on the other hand, they provide greater agility. This special equipment are vessels specially developed for this type of activities: removing these heavy structures.

After cutting the jackets above the waterline, proceed with the removal of the topside, either by hoisting or by jacking. This topside is transferred to a heavy lift vessel, which sets sail for the shipyard or terminal where the topside will be dismantled. [13]

For the removal of the jackets, a similar procedure can be adopted, although not all vessels used to remove the topside are suitable for jacket removal. The structure cutting, depending on local laws, is done below the seabed. However, depending on the planning and the laws, the structure of the jacket can be toppled on the bottom of the sea so that it becomes an artificial coral, instead of being dismantled in a shipyard.

\subsubsection{Leman BH: Using crane barge}

Leman BH platform in England used the single lifting process. As it is a relatively small structure - topside of 1,050 $\mathrm{t}$ and jacket of $584 \mathrm{t}$ - it was able to use a board, in this case Taklift 4 with a lifting capacity of 2,200 t. No deck barge was used, as the crane barge itself brought the structures to the dismantling yard, only $50 \mathrm{~km}$ away from the platform location.

The strategy used for the jacket was total removal and dismantling at the shipyard, for reuse or recycling. [14] 
Golden Eye: Using a special cargo vessel (Special Load Vessel - SLV) or a deep-water construction vessel (Deepwater Construction Vessel - DCV) to remove the topside and a monohull crane (Monohull Crane Vessel - MCV) or a heavy load (Heavy Load Vessel - HLV) to remove the jacket (vessels still under evaluation until the date of the reference article). [4]

Only the removal method of the topside, by single lift, is already defined. The definition of the types of vessel to carry out the activities is still in progress.

\subsubsection{Red Hawk: Using special vessel}

Red Hawk was a SPAR-type platform installed in the Garden Banks field in the Gulf of Mexico. Although it was not a fixed platform, the decommissioning of its topside was carried out like that of a common fixed platform. [15]

The special vessel used was the VB-10000, a Heavy Lift vessel unique in the world, which consists of two parallel hulls with a lattice gantry, each hull being one of the bases of the gantry, and a grab system installed on the gantry. This special vessel is also known as "The Claw" and operates mainly in the Gulf of Mexico, where there is a large platform decommissioning market. [3]

Although it was a floating structure and could be retrofitted in a shipyard for use in another project, the company responsible for SPAR Red Hawk decided on the Rig-to-Reef strategy, as this unit was not designed within the actual GoM requirements for Category 5 hurricanes. Thus, after removing the topside of about 3,800 t with the aid of "The Claw" and a deck barge, the SPAR Red Hawk structure was sunk and became an artificial reef. Unlike Iwaki-Oki, SPAR was not sunk in the region where it operated, but in a position pre-defined by the artificial reef program of the State of Louisiana, USA.

\subsubsection{Halfweg Q1: Using special vessel}

Halfweg Q1 was a small platform, with an upper part of only $500 \mathrm{t}$, not very significant from the point of view of size for this article, but because it used another type of vessel, a jack-up crane platform called Apollo. [17]

The jacket was cut above the water line using abrasive water jet and lifted by connecting the crane straps at the pad eyes previously assembled on the structure.

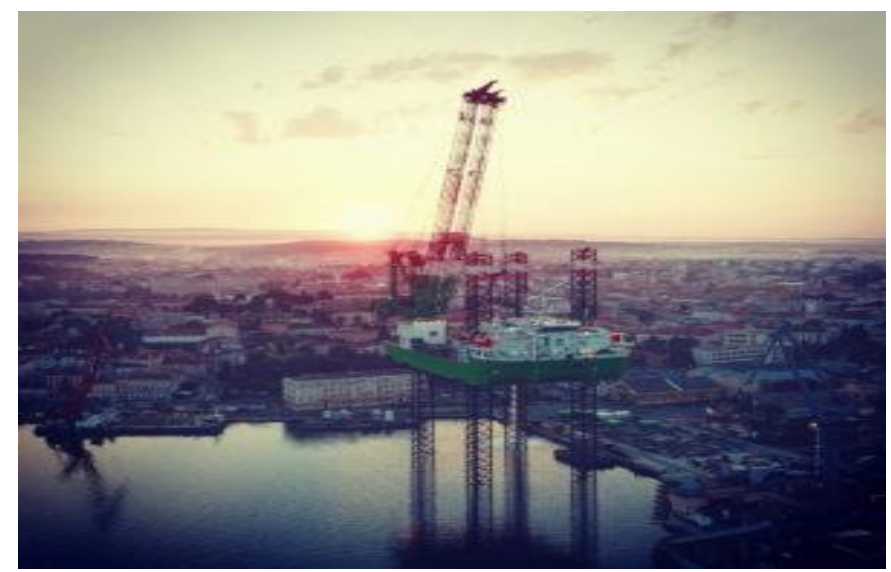

Figure 6 Jack-up Apollo [17]

\subsubsection{Brent: Using special vessel}

The Brent platforms, located in the North Sea, northwest of UK, are another example of removing the topside with the use of a special vessel. In this case, the Pioneering Spirit was used. [18]

The oil from the Brent field is still used as a parameter for the crude oil market and is still produced by the Brent Charlie platform, whose decommissioning plan is still under study.

The Brent Alpha, Bravo and Delta platforms were all decommissioned by the same process. Unlike other specialized vessels, the Pioneering Spirit jacks the structure up. The ship is positioned in such a way that the platform is in the gap between both hulls that make up this catamaran-like ship. Then, jambs are installed on the structure to be removed and just below, still above the water line, the tubular structures are cut. Finally, with the arms already positioned under the jambs, the ship is displaced, jacking the topside upwards. With the topside already disconnected, it is taken to a crane barge or to a heavy load vessel (HLV), to transport the structure to the cutting ground. 
Other platforms used the same process with the Pioneering Spirit, such as Ninian North [21], Tyra [22], Valhall QP [23] and Yme [24]. Brent D was the heaviest structure removed with this method up to now, with 24,000 t, but Pioneering Spirit already supported higher loads in the Johan Sverdrup installation campaign [25], in Norway.

Table 1 Summary of Topside Removals

\begin{tabular}{|l|r|r|l|l|l|l|}
\hline Platform & 13.500 & $\mathrm{t}$ & 2016 & Single Lift & Pioneering Spirit & SLV \\
\hline Yme & 6.000 & $\mathrm{t}$ & 2010 & Removal in parts & Sapura 3000 & Heavy Lift \\
\hline Iwaki & 500 & $\mathrm{t}$ & 2017 & Single Lift & Apollo & $\begin{array}{l}\text { Heavy Lift } \\
\text { Jack-up }\end{array}$ \\
\hline Halfweg Q1 & 16.000 & $\mathrm{t}$ & 2020 & Single Lift & Pioneering Spirit & SLV \\
\hline Brent A & 24.000 & $\mathrm{t}$ & 2019 & Single Lift & Pioneering Spirit & SLV \\
\hline Brent B & 24.000 & $\mathrm{t}$ & 2017 & Single Lift & Pioneering Spirit & SLV \\
\hline Brent D & 12.500 & $\mathrm{t}$ & 2020 & Single Lift & Pioneering Spirit & SLV \\
\hline Ninian North & 19.000 & $\mathrm{t}$ & 2020 & Single Lift & Pioneering Spirit & SLV \\
\hline Tyra East A & 10.500 & $\mathrm{t}$ & 2020 & Single Lift & Pioneering Spirit & SLV \\
\hline Tyra West A & 3.500 & $\mathrm{t}$ & 2019 & Single Lift & Pioneering Spirit & SLV \\
\hline Valhall QP & 4.050 & $\mathrm{t}$ & 2015 & Single Lift & VB-10000 & Heavy Lift \\
\hline Red Hawk & 1.050 & $\mathrm{t}$ & 2017 & Single Lift & Taklift 4 & Crantry Crane \\
\hline Leman BH & 28.700 & $\mathrm{t}$ & 2018 & Removal in parts & Saipem 7000 & SSHLV \\
\hline Miller & 28.000 & $\mathrm{t}$ & 2016 & Removal in parts & Hermod & SSHLV \\
\hline North West Hutton & & & & &
\end{tabular}

\section{SPECIALISED VESSELS}

\subsection{Pioneering Spirit}

The Pioneering Spirit is a catamaran type vessel (with two parallel hulls) developed specifically for the handling of topsides - assembly and removal - up to 48,000 $\mathrm{t}$ and also for jacking up to 25,000 $\mathrm{t}$ jackets and launching submarine pipelines at depths greater than 13,000 feet. [18]

Its operation mode for removing topsides works with the jacket being between the two parallel hulls. On the deck of each hull there are articulated arms that are positioned under support jambs previously assembled during the tubular structure cutting. In order to be able to accurately position the articulated arms, a dynamic positioning system and arm mobility are essential.

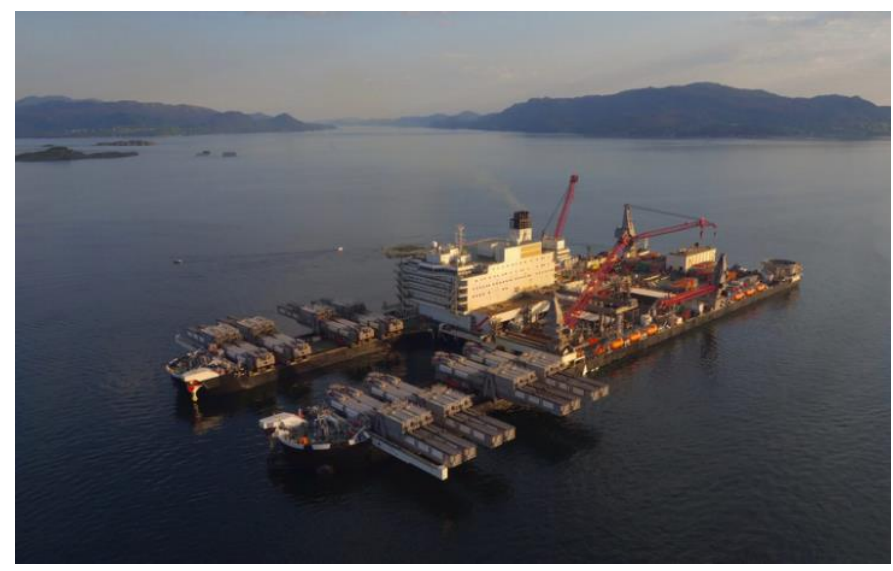

Figure 7 Pioneering Spirit [18]

With the arms already positioned under the support jambs, the structure is jacked up, which is then moved to a heavy lift vessel to transport it to the topside dismantling yard.

\subsection{COSCO Twin-Lift}

The method developed by COSCO for topsides handling consists of the use of two dynamic positioning vessels specially adapted to jack up the topside each one on each edge, being then projected in a mirrored way. After lifting the structure to be removed, the two ships sail in parallel until they reach a third ship, which will be under the topside, between the parallel hulls. This ship is a heavy lift type, specially designed to carry heavy loads on the deck and she must have necessarily a Dynamic Positioning system, as the parallel hulls are. [20]

The challenges of this method are:

- The ability of the two ships to align with each other, both for jacking up and for moving to the heavy lift ship; 
- The control of the capsizing moment and, consequently, the control of ballast and the counterweight system on the deck;

- The necessary structural reinforcements, which make ships asymmetrical in relation to their centre line;

- The dimensioning of the jambs to be installed on the topside to support the weight of the topside.

\subsection{The Claw (VB-10000)}

The VB-10000, better known as "The Claw" is a versatile decommissioning solution developed by Versabar, capable to remove not only the topside, but also the jacket or vessels sunk on the seabed, in addition to units damaged by accidents or hurricanes.

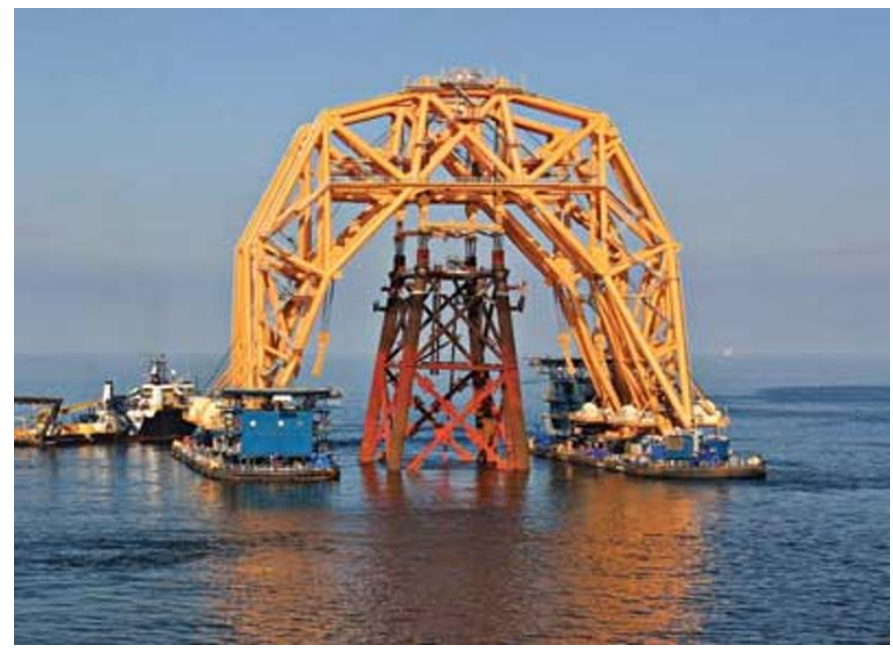

Figure 8 The Claw [16]

The Claw was built in 2010 to meet the growing demand for offshore decommissioning in the Gulf of Mexico, having been awarded by Offshore Technology Conference (OTC) in 2012 with the new technology award.

At the Gulf of Mexico (GoM), the number of fixed platforms in shallow waters has been declining in recent years to quite significant levels in the first fifth of the 21st century. According to Kaiser and Narra [27], more than 40\% of the shallow water activity of the GoM until 2016 was related to decommissioning, of which 2084 were decommissioned structures against 285 new facilities. These numbers can be used as a parameter for the coming years of decommissioning market at the Brazilian coast.

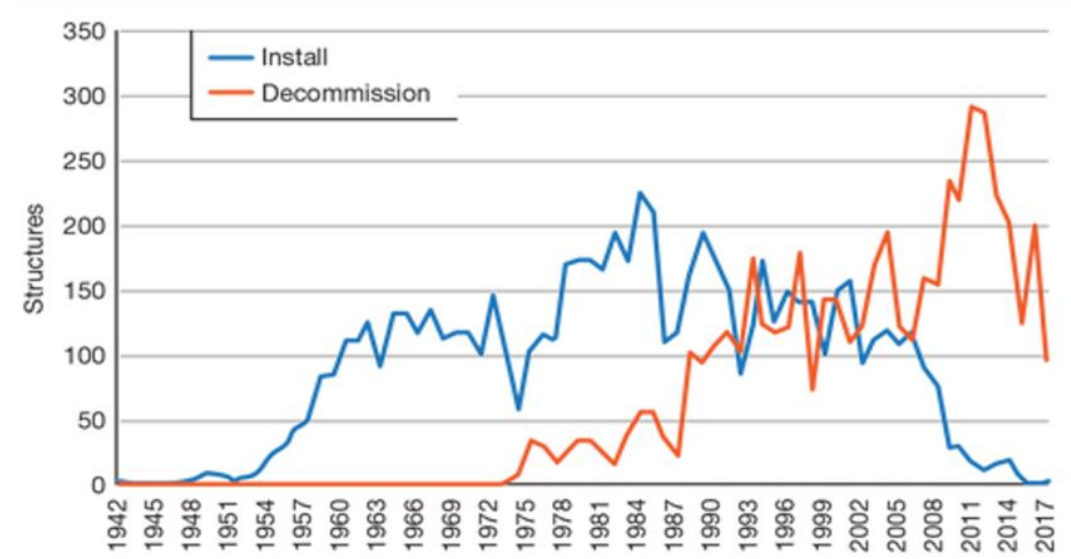

Figure 9 Decommissioning at GoM up to 2017 [3]

\section{CRITERIA OF SELECTION}

Except for very special cases, the strategy of removal is driven mainly by cost. There are some key parameters that shall be considered such as and not limited to:

- Mobilisation / Demobilisation costs;

- Depth of the bottom of the structure to be removed; 
- Use of ROV / divers to carry out the activities under the water;

- Dimensions / Weight of the structures;

- Method of jacket cutting;

- Others.

Although from a technical point of view, some solutions are faster and have a shorter time of exposure to risk on the sea, these solutions are not always adopted, due to the higher cost. The daily costs to hire a specialised vessel are much higher than using conventional solutions with smaller crane barges. Also, as the special vessels are located mainly in the North Hemisphere, the costs for mob / demob are increased to operate in the South Hemisphere and it practically makes unfeasible to hire these specialised vessels. The ongoing studies on decommissioning of platforms in Brazil for the use of specialised vessels face precisely the issue of cost for their use.

\section{CONCLUSION}

Technically, the single removal and transfer for topside dismantling on land is the most advantageous way to decommission the platforms, since the faster the work, the less susceptibility to weather changes, exposure of workers to risk and costs of chartering of ships, in addition to make the logistics easier. The advent of large specialised vessels in the 2010s, such as the Pioneering Spirit, "The Claw" and more recently Sleipnir [26], will allow the removal of increasingly larger structures in less time, serving a growing market worldwide. Although, to reach other markets such as South America and West Africa, it is necessary to increase their economic feasibility.

\section{ACKNOWLEDGEMENTS}

We thank Professor Paulo Roberto Duailibe and Professor Newton Narciso Pereira for his guidance in this work, SOBENA - Brazilian Society of Naval Engineering - which has been producing seminars on this topic of decommissioning of ships and platforms and to AEPET - Petrobrás' Engineers Association for its efforts to develop a sustainable oil industry in Brazil.

\section{REFERENCES}

[1] Cláudio Paschoa, http://pt.oedigital.com/news/descomissionamento-brasil-nova-fronteira-277224, accessed in 08/02/2020;

[2] Yuzo Toya, Yasukoto Fujisaki, Summary of Iwaki Oki Platform Decommissioning, Journal of the Japanese Association for Petroleum Technology, 2012;

[3] Offshore Magazine - Decommissioning activity on the decline in the Gulf of Mexico, 01/08/2018, https://www.offshore-mag.com/field-development/article/16762274/decommissioning-activity-on-the-decline-in-thegulf-of-mexico. Accessed in 08/02/2020.

[4] Shell, Golden Eye Decommissioning Programmes, report $\mathrm{n}^{\circ}$ GDP-S-AA-8203-00001, October/2019, https://assets.publishing.service.gov.uk/ government/uploads/system/uploads/attachment_data/file/846268/GDP-PTS-AA-8203-00001 A08 final.pdf. Accessed in 08/02/2020;

[5] Sapura 3000 Brochure, https://sapuraenergy.com/wp-content/uploads/2015/10/Sapura-3000.pdf. Accessed in 08/02/2020;

[6] Shell, Brent Decommissioning Program, Brent Delta Topside Decommissioning Programme, https://www.shell.co.uk/sustainability/ decommissioning/brent-field-decommissioning/brent-field-downloads/ _jcr_content/par/tabbedcontent/tab_1190828776/textimage.stream/1519761050419/f9e5eb4edfffe625ce2117e308681 8f5d74c491f/brent-delta-topside-decommissioning-programme-june-2015-final-draft.pdf. Accessed in 12/11/2019;

[7]

$$
\text { Shell, Brent Field Topsides Decommissioning Programme }
$$

https://www.shell.co.uk/sustainability/decommissioning/brent-field-decommissioning/brent-field-decommissioningprogramme/_jcr_content/par/tabbedcontent/tab/textimage.stream/1533568113168/49526773a234e2bea1a171685feb4 918573a2127/brent-field-alpha-bravo-charlie-topsides-decommissioning-programme.pdf. Accessed in 12/11/2019;

[8] Eider Alpha http://www.energyglobalnews.com/taqa-converts-eider-alpha-platform-northern-north-sea/. Accessed in 08/02/2020;

[9] British Petroleum, Miller Platform Dismounting, https://twitter.com/bp_plc/status/980145003832819712/photo/1. Accessed in 26/05/2020;

[10] Aker BP - Valhall QP Topside Safely Removed - https://www.akerbp.com/en/valhall-qp-topside-safely-removed. Accessed in 08/02/2020;

[11] Offshore Magazine - Pioneering Spirit Removes Valhall QP Topsides - https://www.offshore-mag.com/rigsvessels/article/14034895/pioneering-spirit-removes-valhall-qp-topsides. Accessed in: 08/02/2020; 
[12] BP North West Hutton Decommission Programme - https://www.bp.com/content/dam/bp/countrysites/en_gb/united-kingdom/home/pdf/North_West_Hutton_Decommissioning_NEW.pdf. Accessed in 08/02/2020;

[13] Atlas Knowledge Topside Removal Options - https://www.atlasknowledge.com/insights/topside-removal-options. Accessed in 08/02/2020;

[14] Shell Leman BH Decommissioning Programme, https://www.shell.co.uk/sustainability/decommissioning/leman-bhdecommissioning/_jcr_content/par/relatedtopics.stream/1438335921551/65cfa1cb08702a42fa7aab673a581be0538200 e2/leman-bh-decommissioning-programme.pdf. Accessed in 08/02/2020;

[15] Offshore Magazine - Red Hawk stands as first spar ever decommissioned in GoM , https://www.offshoremag.com/field-development/article/ 16758430/red-hawk-stands-as-first-spar-ever-decommissioned-in-gom. Accessed in $08 / 02 / 2020$;

[16] Versabar VB-10000 “The Claw" - http://www.vbar.com/vb10000/index.html. Accessed in 08/02/2020.

[17] Deme Group Apollo Jack-up particulars - https://www.deme-group.com/technologies/apollo. Accessed in: 08/02/2020.

[18] Pioneering Spirit [2] https://allseas.com/equipment/pioneering-spirit/ Accessed in 08/02/2020.

[19] Taqa submits decommissioning plan for 30-year-old North Sea platform, https://www.energyvoice.com/oilandgas/north-sea/214471/taqa-submits-decommissioning-plan-for-30-year-old-northsea-platform/. Accessed in 08/02/2020;

[20] COSCO Shipping Twin Lift Solution - https://coscoht.com/projects/decommisioning/. Accessed in 08/02/2020;

[21] Ninian North 'fully ready' for single-lift decommissioning job - https://www.energyvoice.com/events/offshoreeurope/206967/ninian-north-fully-ready-for-single-lift-decommissioning-job/. Accessed in: 08/02/2020;

[22] Pioneering Spirit preparing for North Sea Tyra platform removals - https://www.offshoremag.com/production/article/14168577/pioneering-spirit-preparing-for-north-sea-tyra-platform-removals. Accessed in 08/02/2020;

[23] Valhall QP topside safely removed - https://energynorthern.com/2019/06/17/valhall-qp-topside-safely-removed/. Accessed in 08/02/2020;

[24] Yme platform removed in a single lift - https://www.ogj.com/drilling-production/article/17249488/yme-platformremoved-in-a-single-lift. Accessed in 08/02/2020;

[25] Johan Sverdrup offshore installation completed - https://www.lundin-energy.com/johan-sverdrup-offshoreinstallation-completed/. Accessed in 08/02/2020

[26] Heerema Marine Contractors Sleipnir - https://hmc.heerema.com/fleet/sleipnir/. Accessed in 08/02/2020;

[27] Kaiser, Mark J. \& Narra, Siddhartha, 2018. "A hybrid scenario-based decommissioning forecast for the shallow water U.S. Gulf of Mexico, 2018-2038," Energy, Elsevier, vol. 163(C), pages 1150-1177. The ongoing studies on decommissioning of platforms in Brazil for the use of special ships face precisely the issue of cost for their use. 